\title{
Tradición poética y variante humana en El rayo que no cesa, de Miguel Hernández: metáforas de lo invisible
}

\author{
José Luis FERris \\ Universidad Miguel Hernández de Elche (UMH) \\ ORCID: 0000-0003-237I-5028
}

\begin{abstract}
El rayo que no cesa, segunda obra publicada de Miguel Hernández, ha sido sometida durante décadas a numerosos estudios críticos que han tratado de desentrañar el carácter clásico y vanguardista de esta obra, sus precedentes en la poesía áurea y moderna, tanto en forma como en contenido. Sin embargo, el ingrediente biográfico, determinante en la poesía de Hernández -en él es imposible deslindar vida y obra-, se ha mantenido al margen de estas consideraciones. El presente trabajo trata de aportar a los tradicionales estudios la variante humana apoyándose en nuevos y contrastados datos biográficos que desde 2002 forman parte de una investigación personal. El objetivo es sumar, a los conocimientos filológicos, una visión iluminadora de las circunstancias que motivaron El rayo que no cesa.
\end{abstract}

Keywords: poesía, Hernández, soneto, amor, petrarquismo, símbolo.

El camino recorrido para llegar a la publicación de El rayo que no cesa -una obra determinante en la producción poética de Miguel Hernández-, tiene tantos matices que solo con el estudio pormenorizado de esa evolución lograremos entender su significado y su sentido. Literariamente, el punto de partida lo encontramos en un libro anterior que nunca vio la luz y que, bajo el título de El silbo vulnerado, recogía una suerte de poemas escritos entre 1933 -fecha de la aparición de Perito en lunas, su opera prima- y 1935.

En realidad, El silbo vulnerado tuvo tres etapas diferenciadas y sufrió un proceso de mutación de tres años en los que el poeta, como recuerda Agustín Sánchez Vidal, trabajó «a varias bandas barruntando su voz adulta» (1992: 50). Lo constituyen más de 250 composiciones de muy diversa factura -la polimetría se convierte en recurso preferente- entre las que se pueden distinguir, por este orden, octavas reales (45 piezas excluidas de Perito en lunas), poemas de verso breve (13), décimas de sabor guilleniano (33) y una miscelánea con tendencia a la silva y al poema largo que poblará de odas, elegías, églogas y otras formas pastoriles (hasta 90) los cuadernos de Hernández. Por último, el conjunto desembocará en una serie de poemas amorosos y en los sonetos pastores que anuncian ya El rayo que no cesa.

La primera etapa comprendería, como hemos señalado, el tiempo transcurrido entre la publicación de su primer libro y septiembre de 1933, periodo 
de nueve meses muy marcado por Perito en lunas (octavas, décimas, poemas breves). Tras ese inicial Silbo vulnerado, llegaríamos a un segundo momento que podría darse por concluido a comienzos de 1935. Aquí quedarían englobados sus poemas religiosos y las composiciones que revelan ya una asimilación de la influencia de la Escuela de Vallecas. Son poemas (odas, églogas, elegías) de mayor relajación formal, pero de una gran densidad conceptual, con símbolos religiosos hallados en la naturaleza y ramificaciones teológicas algo complejas. A este Primitivo silbo vulnerado sucedería la tercera y última etapa -en parcial convivencia con la anterior-, de temática eminentemente amorosa, que comprendería el periodo de noviazgo con Josefina Manresa, los últimos meses de 1934 y la primera mitad de 1935, cuando el poeta se traslada definitivamente a Madrid. Se trata de un periodo en el que Hernández se plantea eliminar temas y metros para centrarse, por evolución y en consecuencia, en el soneto amoroso, dando lugar a ese amplio racimo de poemas que la crítica ha clasificado en tres grupos o momentos, a saber: sonetos pertenecientes al Ciclo de El silbo vulnerado (56), la colección llamada propiamente El silbo vulnerado (26) y la versión conocida como Imagen de tu huella (13); un conjunto de composiciones, en fin, que allana el camino hacia su obra más significada, El rayo que no cesa.

\section{Un libro y una crisis}

En febrero de 1935, Hernández se instaló en Madrid por tiempo indefinido. Se habían acabado para él los viajes de ida y vuelta a la capital. Ahora le interesaba alcanzar el éxito literario y conseguir un trabajo estable. Sus relaciones con su gran compañero Ramón Sijé se comenzaban a deteriorar debido a un distanciamiento esencialmente ideológico; alejamiento que a la vuelta de unos meses también sufriría con su novia Josefina Manresa.

A la presencia y el apoyo de autores determinantes para el poeta, como Pablo Neruda y José María de Cossío, había que sumar, como importante influencia en ese nuevo periodo, la llamada Escuela de Vallecas, que le llegaba por dos vías esenciales: la estética y la afectiva. Su encuentro en diciembre de 1934 con el pintor Benjamín Palencia y, a través de él, con toda una serie de artistas que compartían una concepción antiurbana -valga el términodel arte, supuso para Miguel el hallazgo de una plástica que se ajustaba a la perfección a su idea panteísta, rural y predominantemente exaltadora de esa naturaleza que había alimentado su poesía y su teatro. Hasta que Hernández no conoció a Palencia y, sobre todo, al escultor Alberto Sánchez, sus prejuicios acerca de esa ruralidad que definía su propia obra eran muchos.

Hay, no obstante, otro elemento que convierte esta influencia de la Escuela de Vallecas en razón personal y sensible. Hablamos de su relación con otra artista del grupo: la pintora Maruja Mallo. Miguel la había conocido, 
probablemente, a través de otros artistas, aunque su encuentro más determinante se produjo en febrero de I935 en casa de Neruda. Por ese tiempo, la pintora tenía ya un prestigio bien ganado que la situaba en la elite del arte español. Su personalidad arrolladora y excéntrica era una simple prueba de la independencia que definía su carácter de mujer poco dada a atavismos afectivos.

Lo cierto es que en la primavera de 1935 Miguel Hernández se sentía ya integrado en la vida cultural madrileña, sobre todo, tras aceptar la generosa oferta de trabajo que le propuso José María de Cossío, invitándole a colaborar con él, como secretario particular, en el último tomo de la enciclopedia Los toros, obra que dirigía Ortega y Gasset y de la que Cossío es director literario. Pero, además, esa primavera madrileña habría de ser también trascendente para Hernández gracias a su encuentro con el poeta Vicente Aleixandre. Si clara parecía la influencia de la Escuela de Vallecas, no iba a ser menor el descubrimiento de esa vía neorromántica que le proporcionaría el surrealismo poético de Neruda y de Aleixandre. Pese a todo, a la par que sus nuevas experiencias literarias, Miguel iba a sufrir un proceso de transformación ideológica y, consecuentemente, también afectiva que conllevaba al mismo tiempo un replanteamiento de su relación con Josefina Manresa. El poeta estaba abriendo los ojos a una realidad muy distinta que le llevaría a reconocer el retroceso de esas costumbres de las que había sido víctima y que ella, su novia, encarnaba todavía.

La relación entre ellos se dio por concluida en julio de 1935. Quedaban atrás los poemas de amor inspirados en la joven costurera de pelo negro y ondulado; los de ese Silbo vulnerado sin publicar que tenían la honda marca de Josefina: «Primavera celosa», «Tus cartas son un vino», «Todo me sobra», y un nutrido grupo de sonetos campesinos donde la voz del poeta es lamento y pena siempre por ese exceso de puritanismo de la amada que le arranca un «ay» constante y que le impide realizarse como amante y como hombre.

Buena parte de los biógrafos del poeta conviene en atribuir la citada separación a la crisis ideológica de Miguel y a factores muchas veces externos, pero datos suficientemente contrastados nos llevan a entender que ese distanciamiento con Josefina fue provocado por la aparición de Maruja Mallo en la vida del poeta (Ferris 2004b: 209-2I7). Son muchas las evidencias que nos conducen a la intensa y apasionada relación que surgió entre la pintora y Hernández desde su encuentro en casa de Neruda. Miguel, que no había descartado en ningún momento su dedicación al teatro con un nuevo drama que le rondaba esos días, Los hijos de la piedra, había recibido el apoyo de Maruja, que se ocuparía de los decorados de la obra. Pero además de estas colaboraciones artísticas, hay pruebas de que realizaron juntos más de un viaje y que pasaron inolvidables noches al amparo de la naturaleza. El texto que sigue corresponde a Maruja Mallo y tiene un gran valor documental, 
ya que en él se recoge, con una prosa llena de sensualidad, su recuerdo del poeta y toda la iconografía vallecana que aparece en su pintura y, consecuentemente, en los poemas de Hernández:

Por nuestro panteísmo y culto a la conjugación de las leyes físicas con la armonía cósmica, comprendí su conocimiento intuitivo de la influencia de los astros sobre los reinos de nuestro planeta: como ser sideral no tenía espacio para la sorpresa, ni tiempo ante lo inesperado [...]. Intuyó mi impulso incontrolable para la plastificación de la Región del trabajo, Sorpresa del trigo, El canto de las espigas, que iniciaba yo en esa hora, donde entraba en la concepción muralista a gran tamaño cuyo contenido o síntesis eran: agua-tierra-peztrigo y red-hoz; azul-plata o rojo-oro [...]. Sospechaba yo que sus descargas ideológicas participaban en ese ritual y convinimos atravesar las soleadas tierras de Castilla la Nueva, dirigiéndonos al Sur [...] donde nos informaron que Perales era la zona forestal de las eras en agosto. Emprendimos el camino sorprendidos ante la magnificencia del aire cubierto mágicamente de pepitas de oro [...]. A nuestra izquierda se deslizaba un afluente del Tajo, el calor del solsticio de verano abrasaba y nos arrojamos al agua. Al caminar nuevamente, nos sorprendimos de que a los cinco minutos nuestras ropas estaban totalmente secas [...] (Mallo I979).

Recapitulando lo comentado hasta ahora, el proceso literario y amoroso de Hernández no es otra cosa que una depuración del componente religioso de su poesía hacia metas más libres y, sobre todo, el preciso testimonio de una crisis sentimental que deriva en una crisis de identidad de mayor calado. Hemos visto que, hacia el mes de junio de 1935 , tras un copioso epistolario dedicado a Josefina Manresa y una serie de sonetos pastoriles inspirados en ella, el poeta comenzó a dar señales de un duro cambio de actitud. En cualquiera de esas composiciones era cabalmente distinguible el sujeto al que iban destinadas: una amada unida a la castidad, a la sencillez, a la ingenuidad, pero también la encarnación de un ser capaz de convertir el común instinto masculino en razón de pecado y de lujuria. «Para mí -confesaba Josefina al hispanista Dario Puccini en 197I- un beso del novio era perder el honor y en esa actitud siempre fui dura, además que yo lo quería demasiado y procuré tenerlo siempre con la misma ilusión, para nuestra felicidad» (Morelli 20II: 124). Resumiendo, todos los sonetos atribuibles a la joven costurera estaban impulsados por el mismo aliento: el sentimiento dolorido, la melancolía del enamorado y la pena que provoca el deseo erótico no materializado.

Diez serán los sonetos generados por Josefina que, finalmente, pasarán a ocupar un lugar en El rayo que no cesa. En claro contraste, la receptora de las nuevas composiciones que Miguel escribió entre mayo y septiembre de 1935 no parecía ser otra que Maruja Mallo. Acerca de esta afirmación es necesario aludir a la conversación que Gabriele Morelli mantuvo en 1964, durante 
la elaboración de su tesis doctoral sobre el poeta, con la viuda de Hernández. En ese primer encuentro, Morelli comenzó preguntando a Josefina por los poemas del libro El rayo que no cesa que su esposo le había dedicado, «pero Josefina -confesaba el hispanista italiano- silenció en parte mi pregunta, reconociendo que sólo algunos de estos poemas estaban dedicados a ella» (2009: 259-260).

Estas palabras del profesor Morelli refrendan la idea de que Miguel, tras su etapa aldeana, había dado un paso decisivo en su poesía. La experiencia madrileña (tanto humana como estética) le había alejado del conservadurismo, de sus lecturas del Siglo de Oro, de una lírica anclada a la tradición, y ahora propiciaba la creación de unos sonetos donde adquirían pleno sentido -como indica Cano Ballesta- «las osadías de la expresión impura y desgarrada» (1997: 2I). Los versos habían perdido el tono melancólico del lamento y se llenaban de pasión y de sentido hondo y grave, de expresión más viva y desatada, de una experiencia amorosa más sincera, profunda e irreprimible.

Al hilo de las citadas palabras de Cano Ballesta y puestos a escoger esa imagen rotunda, simbólica y precisa que marque el cambio, el viraje hacia ese amor nuevo y telúrico, será, por excelencia, el toro la elegida. Debido a caprichos del azar, el único trabajo retribuido que tuvo el poeta por aquel tiempo fue, como hemos visto, en una oficina de la editorial Espasa-Calpe, junto a Cossío, elaborando biografías de toreros. Según Leopoldo de Luis, «la lectura continuada de materia taurina influyó en Miguel para la adopción del tema en su poesía amorosa» (1998: 30). Pero ocurre que la coincidencia de esa tarea diaria con la aparición de Maruja Mallo y con el alejamiento de los postulados estéticos e ideológicos que encarnaban su pasado inmediato, le llevarían, con la displicencia de un hallazgo imprevisto, a aprovechar el tema del toro como eje de sus nuevas composiciones, así como a elevarlo a una simbología de signo trágico, noble y masculino. «Ahí va otro soneto taurino -dirá el poeta a Cossío en carta de 3I de julio de I935-: el ambiente cornudo en el que vivo, me hace cantar tauromáquicamente a todas horas». Pero Miguel iba a ir más allá y pasó de lo taurino a lo táurico. Concentró toda su cosmovisión en una serie de sonetos que mostraban el destino y el dolor de legiones de enamorados:

Sabemos que estos poemas se escribieron en 1935 -vuelve a señalar De Luis-. Su frecuentación del tema por mor del trabajo editorial le llevaría de la mano a resumir, como bien dice él mismo, una descripción. El siguiente paso será tornar el toro en símbolo del destino del amante e identificarlo con su pena, con su pasión, con su ímpetu (1998:30).

Estos sonetos dieron lugar a la serie de poemas taurinos que tuvieron su inicio, según sugieren José María Balcells (2002: 15) y Leopoldo de Luis (1998: 30), el I4 de julio de 1935, cuando en carta a Cossío, Hernández deta- 
llaba sus trabajos editoriales y unía a la correspondencia la primera composición inspirada en la nueva simbología: «También le mando un soneto, que no sé si le gustará, para su descripción del toro; lo he hecho con la mejor voluntad. Ahí va» ${ }^{1}$.

La receptora de esas nuevas composiciones respondía ya al perfil exacto de una mujer desinhibida, libre y dispuesta a contravenir cualquier ley que se interpusiera entre ella y sus deseos. Y para diferenciar mejor este amor del otro, de la muchacha que el poeta había dejado en Orihuela, el propio Hernández recurrirá al código de esa iconografía que había hecho suya tras su contacto con la Escuela de Vallecas, y que compartía con la simbología plástica de la artista gallega. Al menos, en cuatro sonetos de Imagen de tu huella escritos en esa primera fase de asombro y vitalismo -el poeta se manifiesta feliz tras sus iniciáticos encuentros campestres con la artista-, se habla ya de tactos, de manos, de labios rojos que le llenan de dulces campanarios, de noctámbulos ardores. La nueva amada le ha dado la dimensión de varón que tanto ansiaba, la condición plena y masculina tras consumar el rito amoroso - «mi voz sin tu tacto se afemina $»^{2}$ - en medio de esos campos gozosos de cosechas: «Es el tiempo del macho y de la hembra, / y una necesidad, no una costumbre, / besar, amar en medio de esta lumbre / que el destino decide de la siembra» ${ }^{3}$. Un sencillo rastreo por estos cuatro sonetos nos facilita, por último, una fuente de semejanzas con el texto arriba firmado por Maruja Mallo y en el que narra su bucólica escapada con Miguel por las tierras de Perales y Morata de Tajuña. Desde el primer poema -en el que curiosamente trata a la amada de usted-, los términos que aparecen corresponden a esos paisajes y a ese léxico de reciente adquisición que lleva el sello inconfundible del grupo vallecano y la materia elemental de la iconografía empleada por la pintora: abismos, barrancas, vegetales, huesos, espinos, campanarios, cardos, hinojos, cumbre, relámpago, siembra, esquilas, arboledas, campos... Solo en el libro en que culminará todo este proceso, El rayo que no cesa, el poeta alterará el tono de estas composiciones para imponerles un signo trágico al sentirse burlado y severamente herido por el desprecio de la amada.

Pero la vida continuaba y aquel verano del 1935, entrados ya en agosto, el poeta se animó a viajar a Cartagena aprovechando una invitación del matrimonio de escritores Carmen Conde y Antonio Oliver, viejos amigos, para participar en los actos de homenaje a Lope de Vega por el tricentenario de su muerte. Por esas fechas, su trabajo en la enciclopedia taurina le permitía ausentarse unos días de la editorial y, por otra parte, su controvertida relación con Maruja Mallo le había provocado tal estado de desesperación y

I Carta a Cossío fechada en Madrid el I4 de julio de 1935 (Hernández 2010: 1539-40).

2 Verso II del soneto «Mis ojos sin tus ojos, no son ojos» (Hernández 20IO: 4I4).

3 Segunda estrofa del soneto «Ya se desembaraza y se desmembra» (Hernández 2010: 4I4). 
abatimiento que le exigía cambiar de aires. De todo ello iba dando puntual noticia a José María de Cossío, que esos días se encontraba ya en Santander, en su casona de Tudanca: «Ahí va otro soneto taurino: el ambiente cornudo en que vivo me hace cantar tauromáquicamente a todas horas...»».

Es difícil saber con certeza a qué soneto se refería el poeta, aunque sí tenemos razones para creer que el primero que envió a su jefe literario diecisiete días atrás, el I4 de julio de I937, era el poema I4 - «Silencio de metal triste y sonoro»- de su futuro libro El rayo que no cesa; así lo entendieron, como ya señalamos, Leopoldo de Luis y J. M. Balcells en diferentes trabajos. Respecto a la segunda composición que envió a Cossío, tres son los sonetos de El rayo que bien pudieron acompañar la misiva, a saber: 17 «El toro sabe al fin de la corrida», 23 "Como el toro he nacido para el luto» y 28 «La muerte, toda llena de agujeros» ${ }^{5}$. En los tres poemas, el autor se identifica (insistiendo en el ambiente «cornudo» que le rodea) con el animal que se crece ante el castigo, pero que acaba finalmente engañado: «como el toro burlado, como el toro» ${ }^{6}$.

Durante su estancia en Cartagena junto a Conde, Oliver y otros conocidos, Hernández tuvo ocasión de visitar Cabo de Palos y recordar, frente al mar, al escritor Gabriel Miró y al poeta Andrés Cegarra, fallecido en 1928 (Ferris 2007: 375-377). Entre los asistentes, se encontraba la hermana de Andrés, María Cegarra Salcedo. Miguel se vio de nuevo con esa amiga que conoció en Orihuela en octubre de 1932, en la inauguración del busto a Miró en la Glorieta oriolana, y que volvería a ver en julio de 1933 en su primera visita a Cartagena. Pero ahora Hernández no era el mismo de entonces. La crisis sentimental que le tenía herido tras su ruptura con Josefina y su todavía encendido desengaño amoroso con la pintora, le convertían en un hombre vulnerable. Ni su novia de Orihuela era mujer para él por señaladas diferencias, ni Maruja Mallo le daba otra opción que el desencanto y la frustración. Sin embargo, María Cegarra aparecía y se mostraba en aquel momento como la síntesis de lo mejor de ambas: la llaneza humana de una muchacha sin sofisticación alguna y el talento de una mujer inteligente y comprensiva que además admira a Miguel. María trabajaba como perito químico en unos laboratorios de análisis minerales y, además, era poeta. Ese mismo año de 1935 había publicado su primera obra poética en la colección Sudeste, Cristales míos, y no descartaba dedicarse también a la docencia como profesora de Física y Química. La realidad era que el poeta se encontraba en el lugar más

4 Carta a Cossío fechada en Madrid el 3i de julio de 1935 (Hernández 2010: 1544).

5 Coincidimos en esta apreciación con el profesor Balcells, aunque en su introducción a $E l$ rayo que no cesa (2002: I6) indica erróneamente que el soneto «La muerte, toda llena de agujeros» ocupa el lugar 25 de El rayo que no cesa, cuando en realidad es el número 28.

6 Último verso del soneto 23, "Como el toro he nacido para el luto», de El rayo que no cesa (Hernández 20I0: 432). 
inopinado a la mujer que podía resolver la crisis que le asistía, y el hecho que desencadenó tal supuesto fue la visita que realizó Hernández esos días a La Unión, el pueblo de María Cegarra, con la que paseó y recorrió el paisaje de las minas bajo una puesta de sol que no se borraría de la memoria de Miguel en mucho tiempo.

A su regreso a Madrid, el pensamiento del poeta estaba poseído por la muchacha murciana, de hecho, ese mismo mes de septiembre, tras su vuelta, Miguel empezó a verter en el molde de los catorce versos los estímulos que, desde la distancia, le sugería y le provocaba la muchacha de La Unión. A primeros de octubre, el poeta ya tenía compuestos varios sonetos dedicados a María Cegarra, perfectamente diferenciados del resto de composiciones inspiradas en Josefina o en Maruja Mallo por el tono que empleaba en ellos, por el componente platónico o el aire sereno que tanto se adecuaba al sentimiento que la muchacha le había inspirado y que poco o nada tenía que ver con el lamento pastoril o con el trágico sino del toro. Sin embargo, el poeta pronto sufrirá un golpe de melancolía debido al silencio (y al rechazo sutil) de la poeta murciana, un hecho que venía a sumarse a su transformación ideológica, ese cambio que obligaba a derribar los ideales pasados y a enfrentarse a un futuro confuso.

Entre finales de octubre y comienzos de noviembre de 1935, Miguel, después de dos misivas que no tuvieron respuesta, escribió una tercera y última carta a María. La joven tampoco respondió, cortando así, con un silencio hiriente, una relación en la que Hernández había puesto enormes ilusiones. Parece claro que el poeta no tuvo tampoco suerte con esa muchacha, reduciéndose aquel proyecto amoroso a lo que José María Balcells ha definido como «una amistad que pudo alcanzar momentos de devaneo platonizante, pero que difícilmente puede calificarse como experiencia» (1995: 170).

\section{Metáforas de lo invisible}

Con todo lo analizado hasta ahora, la situación del poeta podría reconstruirse sin recurrir demasiado a la imaginación. Pero aquí parece necesario hacer un alto en el camino para recordar que el objeto de este trabajo es analizar la variante humana, esto es, el referente vital del poeta que generó, de modo invisible, metáforas de un hondísimo calado. No es nuestro propósito, empero, insistir en una tarea meramente filológica ante el autor que nos ocupa. Y la tentación es mucha cuando se tiene delante un libro cuya lectura última nos invita a hablar del canon literario que sujeta el conjunto, de intertextualidades áureas y contemporáneas, de las lecturas petrarquizantes del Siglo de Oro que acompañaron a Miguel o de esos referentes estéticos de cita obligada que ventean el libro con aires y con ecos de San Juan 
de la Cruz, Garcilaso, Góngora, Quevedo, Rosalía de Castro, Juan Ramón Jiménez, Aleixandre, Lorca, Neruda...

En este sentido debemos recordar que son numerosas las opiniones que insisten en desestimar el valor autobiográfico de los poemas de El rayo que no cesa; entre ellas, Carmen Alemany, para quien el poeta expresó su «mal de amores» con los códigos amorosos de siempre, esto es, sirviéndose de modelos de mujer moldeados o no por el canon literario (2013: 77). Opinión con la que coinciden las profesoras María Dolores Martos Pérez (2004: 269) y Tania Domínguez García (2004: 283-284).

Si bien, en la forma, los poemas de El rayo que no cesa pueden considerarse herederos de la poesía áurea, como hemos visto, la tesis del profesor Borja Navarro Colorado es que el aliento humano que alimenta esta obra (el tratamiento semántico y el material lingüístico que la sostiene) es profundamente suyo, experiencia viva, «totalmente original y único comparado con la tradición clásica» (2020: 558). Este debate -si se le puede considerar así- no es nuevo. De hecho, frente a las opiniones expuestas, la posibilidad de poner rostro, incluso nombre y apellidos a los poemas de El rayo que no cesa, se remonta a más de dos décadas. En I995 ya afirmaba José María Balcells en su artículo «De Josefina a María, y de María a Maruja» (I995: I63-I7I) que, pese a ser visto como un libro inspirado en el amor de una única amada, «son tres las musas involucradas en la confección de El rayo que no cesa: Josefina Manresa, María Cegarra y Maruja Mallo». Más adelante, y tomando como apoyo los textos y cartas de Miguel Hernández, el profesor ponía al lector en la pista de esa hipótesis, aunque confesando al mismo tiempo la complejidad de especificar:

qué poemas del libro pudieron hacer brotar cada una de ellas. La tarea es interesantísima -añadía Balcells-, aunque tropieza con onerosos imponderables. Empero, no cabe duda que se puede avanzar en el camino de atribuir textos a una $\mathrm{u}$ a otra mujer, y vamos a intentarlo ahora con algunos ejemplos, dejando para otra oportunidad continuar discurriendo sobre el problema de las voces líricas relacionadas con mujeres diferentes en El rayo que no cesa (1995: I63-I7I).

Nuestra confianza en los viejos postulados del Balcells tuvo su respuesta en 2002, en la primera edición de Miguel Hernández, pasiones, cárcel y muerte de un poeta. En esa biografía asumimos con escrúpulo y entusiasmo el viejo reto del profesor, el de profundizar en la interesantísima tarea de estudiar la vida del poeta, sus relaciones humanas y artísticas, en el arduo periodo de la redacción de El rayo que no cesa; una labor efectivamente compleja que nos llevó a distinguir las tres voces que parecían fundirse en el libro amoroso de Hernández, de modo que las tres mujeres que venían habitando y compartiendo un cuerpo único, el de la amada del poeta, tuvieran su co- 
rrespondiente herencia lírica. Hoy, gracias a la aparición de nuevos materiales (Alemany 20I3; Riquelme 2015, 2019; Morelli 20II; Ferris 2016...)-desde cierta correspondencia inédita de y sobre Hernández, de Josefina Manresa, Puccini y Aleixandre, a nuevas monografías sobre el tema-, nos permitimos reconstruir el proceso de elaboración de El rayo que no cesa y proponer, al mismo tiempo, una nueva y más consistente interpretación biográfica de los poemas que lo conforman; una tarea de la que dimos cuenta por primera vez, como hemos señalado, en 2002, y que hemos ido desarrollando y afirmando a lo largo de estos años, en especial en 2010 y 20I6, con nuevas ediciones, revisadas y actualizadas, de nuestro ensayo biográfico ${ }^{7}$.

\section{Esbozos y poemas de El rayo que no cesa}

Explicado este punto, sin ánimo de restringir la imaginación del lector y siempre que los datos lo permitan, nuestra legítima misión ha sido poner rostro a unos poemas donde el peso de lo humano, de lo vivido, iguala (e incluso supera) cualquier canon literario. Y lo primero que debemos subrayar, en este sentido, es que El rayo que no cesa no es más que el resultado de una selección de poemas forjados a lo largo de año y medio de producción, es decir, entre mediados de 1934 y finales de $1935^{\circ}$.

A lo largo de ese periodo que comprende, como experiencia vital, el noviazgo con Josefina Manresa, el asentamiento en Madrid del poeta, su paso por dos situaciones amorosas de distinto calado (Maruja Mallo y María Cegarra) y el adiós a Ramón Sijé -fallecido en diciembre de 1935-, Miguel dejó escritos dos esbozos (manuscritos, cuadernos) anteriores al libro definitivo, es decir, una versión primitiva de los sonetos amorosos y otra intermedia. Del primer conjunto se tuvo información en 1949, cuando Cossío editó en Argentina, acompañando la edición de El rayo que no cesa (Hernández 1949), una primera versión titulada El silbo vulnerado, compuesta por 26 sonetos, que el escritor santanderino calificaba de borrador de un proyecto primitivo que no llegó a publicarse. Por otra parte, en 195I, Juan Guerrero Zamora daba a conocer otra versión de los sonetos amorosos titulada Imagen de tu huella (Guerrero 195I); se trataba de un conjunto de 13 poemas que repetía, con ligeros cambios, 8 composiciones del cuaderno anterior y que servía de intersección, a nuestro entender (como así trataremos de confir-

\footnotetext{
7 A las tres ediciones del libro Miguel Hernández. Pasiones, cárcel y muerte de un poeta que vieron la luz, revisadas y ampliadas en los años 2002, 2010 y 2016, hay que añadir dos trabajos sobre el tema publicados, respectivamente, en la revista Canelobre y en el volumen de Actas del II Congreso Internacional dedicado a Miguel Hernández: «Eros y Psique en El rayo que no cesa» (2009: 48-67) y «La amada plural en El rayo que no cesa» (2004a: 49-78).

8 En este punto coincidimos con los datos aportados por José María de Cossío, Juan Guerrero Zamora, Dario Puccini, Leopoldo de Luis, Agustín Sánchez Vidal y Carmen Alemany.
} 
mar), entre El silbo vulnerado y El rayo que no cesa. «El verano de 1935 -señala Leopoldo de Luis- resulta, sin duda, clave, como época en que se revisan las dos versiones y se prepara el original para la colección Héroe...» (I998: 34).

Sin depreciar ese «magma textual», el planteamiento que debió de hacerse Miguel Hernández ante la inminente publicación de su nuevo libro podría ajustarse a los pasos que vamos a describir en las siguientes líneas. Y el primero de ellos nos sitúa junto a un poeta que sabe que la obra que va a publicar es, ante todo, un poemario amoroso concebido sobre el molde del soneto. Esto le llevaría, por un lado, a examinar los 25 sonetos que formaban parte de El silbo vulnerado -el esbozo no publicado que guardaba Cossío-, ese cuaderno que fue concebido al amor de Josefina Manresa y que conservaba intacto un tono religioso y un aire pastoril que creía ya superados; por otro lado, se enfrentaría a 22 composiciones nuevas -20 de ellas sonetosque había escrito en Madrid a partir de tres acontecimientos relevantes: su relación con Maruja Mallo (hallazgo, deslumbramiento, consumación del amor y desengaño), su trabajo en Espasa-Calpe (descubrimiento del símbolo táurico) y su experiencia platonizante con la poeta María Cegarra. Esta veintena de poemas, como hemos visto, se distanciaba en acento y profundidad del universo anterior (de esa moral provinciana que reprimía los impulsos del enamorado), pero atendía a tres momentos cronológicamente identificables en ese acelerado proceso de cambios y de contactos humanos y artísticos: su iniciática aventura sexual con Mallo (antes de incorporar a su obra la simbología del toro), los poemas del ciclo táurico (a partir del soneto que inaugura la serie -«Silencio de metal triste y sonoro»-, escrito en julio de i935) y el periodo posterior al 27 de agosto de ese año, tras su encuentro con María Cegarra en Cartagena. De los primeros devaneos amorosos de Hernández con la pintora surgieron 5 sonetos de una factura renovada, con un léxico transformado, evolucionado, que sin entrar en el tono trágico de los sonetos posteriores -el toro y el rayo no aparecen en ninguno de ellos-, ofrecían ya una visión terrestre y material de la existencia. Los sonetos que sí respondían a esa simbología del toro, junto a un caudal metafórico de términos propios de la cosmovisión hernandiana, alcanzaban la cifra de 13 y coincidían en su realización con dos hechos importantes en la biografía del poeta: el contacto directo y diario con el mundo de la tauromaquia gracias a su trabajo en la monumental enciclopedia de Los toros, y el desengaño amoroso en el que había derivado su historia con Maruja Mallo. En tercer lugar, había sobre la mesa del poeta 5 sonetos que resumían una historia truncada y sin apenas comienzo, la misma que le puso en los labios María Cegarra y que se quedó en una sencilla y triste espera. En ninguno de estos poemas aparece el tema taurino, aunque sí lo hacen ciertos recuerdos de la amada fugaz: el hermano fallecido que tanta ausencia dejó en el hogar de la 
muchacha, el paisaje minero, el silencio de ella, la soledad y los pétalos que un día colocó en sus manos.

Alcanzado este punto, Hernández debía seleccionar los poemas que iban a formar parte de ese original que esperaba Altolaguirre para su publicación. Recapitulando, eran 25 (El silbo vulnerado) y 22 (de nueva creación) las composiciones de las que tenía que partir. El autor debía de ser consciente de que el material poético que tenía sobre la mesa, más allá de los referentes clásicos que lo pudieron alentar, respondía a la inspiración de tres mujeres distintas. Una de ellas, Josefina Manresa, estaba presente en los sonetos de El silbo vulnerado, y de ellos salvará diez que conservan los vestigios de un amor aldeano. Hablamos de los sonetos 4, 5, 6, 7, 9, IO, II, I2, I8 y I9 de $E l$ rayo: «Me tiraste un limón, y tan amargo», «Tu corazón, una naranja helada», «Umbrío por la pena, casi bruno», «Después de haber cavado este barbecho», «Fuera menos penado si no fuera», «Tengo estos huesos hechos a las penas», «Te me mueres de casta y de sencilla»", «Una querencia tengo por tu acento», «Ya de su creación, tal vez, alhaja» y «Yo sé que ver y oír a un triste enfada». Todos ellos procedían, pues, de versiones anteriores y fueron escritos, con ligeras variantes, en 1934, antes, al menos, del establecimiento de Miguel en Madrid.

El paso siguiente consistía en una profunda revisión de los 22 poemas de amor creados en 1935. La mayoría de ellos tenía un significado fatalista, si por tal se entiende la exaltación de la pena amorosa y de la crisis de identidad que suscitó en el poeta la dependencia de otro ser sin cuya presencia no se ve realizado como hombre ("y mi voz sin tu trato se afemina», Hernández 2010: 4I4). La voz quejumbrosa, doliente o desalentada de Miguel aparecía en casi todas las composiciones, por lo que resultaba aconsejable, en aras de un tono común y de una mayor cohesión, eliminar los poemas de signo positivo y vitalista. Había, sobre todo, cuatro de ellos que eran el puro ensalzamiento del hallazgo del amor físico, la libertad de los sentidos y la celebración de esa iniciación sexual que se vio por fin cumplida en los brazos de Maruja Mallo. Hernández sabía que esos cuatro poemas - «Astros momificados y bravíos», «Mis ojos, sin tus ojos, no son ojos», «Ya se desembaraza y se desmembra» y «Pirotécnicos pórticos de azahares»-, eran el testimonio de ese momento tan especial en su vida y los apartó del conjunto -más tarde aparecerán entre los sonetos de Imagen de tu huella-. Y es en esos sonetos de patente vocación sexual, de gratitud y de amor tras el acceso carnal del poeta, donde Miguel dejaba ya un rastro de términos y fórmulas que desarrollaría posteriormente, acaso como un código entre él y la artista gallega, en los poemas de signo trágico de El rayo que no cesa.

9 Este poema apareció publicado, con algunas variantes, con el título de «Pastora de mis besos», en la revista talaverana Rumbos de Víctor González Gil el I5 de junio de 1935, poco antes de la ruptura entre Hernández y Josefina Manresa. 
Convendría recordar el texto descriptivo de la artista sobre el viaje a Morata de Tajuña, u observar alguna de sus piezas o de sus proyectos pictóricos de I935, para encontrar una serie de semejanzas verdaderamente asombrosas entre obra plástica y poema:

\begin{abstract}
Estos encuentros campestres con la pintora gallega -sostiene Juan Cano Ballesta- hallan su cenit en una apasionada aventura amorosa de gran impacto vital y artístico para el hombre y el poeta, que escribe muchos sonetos que son fruto directo de esta experiencia, primero de exaltación amorosa y después de trágico desengaño (20I0: 9I).
\end{abstract}

Insistiendo en ese impacto y en esa influencia, coincidiríamos con José-Carlos Mainer cuando sostiene que «el cuadro El asombro de las espigas de Maruja Mallo, quizá el más conocido de cuantos pintó en esta nueva época, podría ser un soneto hernandiano» (I993: 32). El poeta era consciente de que, cuando su pensamiento creativo lo ocupaba la pintora, sus versos se llenaban de esa iconografía vallecana que ambos llegaron a compartir: retamas, barrancos, campanarios, calvarios, hinojos, barbechos, cardos, grama, rayos, huracanes, espigas, pescados... Pero los poemas inspirados por ella, y que se incluyeron definitivamente en el libro, tenían, además, la simbología fatalista que provocó en él la desdeñosa actitud de la mujer una vez satisfecha su curiosidad sexual con el poeta. Miguel cantó entonces a ese amor traicionado en las mejores horas de entrega y confianza. Y su manera de transmitir ese sufrimiento, ese sentimiento de criatura burlada, fue identificándose con el toro: animal que encarna la nobleza y la bravura, pero también el ultraje y el destino trágico. Estamos ante la colección de sonetos táuricos que responden a ese momento crítico de Miguel en el que ha pasado de amante dichoso a poeta seriamente herido. Al igual que el toro marcado a fuego por un hierro, la recuperación de la propia identidad ha de pasar, sin otro remedio, por la mujer amada que es, al mismo tiempo, la autora de esa aniquilación; conflicto este que no tiene solución, pero que resulta muy eficaz a la hora de alcanzar esa tensión nunca satisfecha de la que se sirve el petrarquismo.

Son catorce los poemas inspirados en Mallo que podemos situar en la órbita de esa vocación renovada y trágica que vertebra El rayo que no cesa, y que fueron escritos a partir de julio de I935, cuando Hernández envía a Cossío, junto a una carta, el soneto I4, "Silencio de metal triste y sonoro», primero de la serie si nos acogemos a la opinión de Juan Guerrero Zamora y de Leopoldo de Luis.

Miguel Hernández debía de ser consciente de que «Silencio de metal triste y sonoro", así como las trece composiciones que le seguirían en la cadena creadora, respondía a otro momento, a otro estímulo, a otra realidad y a otra amada. A cualquier conocedor de la obra amorosa del autor de Orihuela, empezando por el mismo Cossío, le hubiera costado mucho aceptar, de no 
ser así, que la musa de Miguel fuera capaz de extraer del poeta expresiones del tipo «amorosa fiera hambrienta», «liebre libre y loca», «amoroso cataclismo», «sensual movimiento memorable»y otras fórmulas de semejante perfil. Hasta entonces, la destinataria de sus versos no había sido otra que esa mujer llena de pudores femeninos, de marcado puritanismo de aldea. Pero ahora se trataba de una historia consumada, física y carnal, y de sus consecuencias simbólicas, metafísicas si se quiere, pero, ante todo, humanas. «El rayo que no cesa no hay por qué ir a buscarlo en la tradición literaria -señala Eutimio Martín-, sino en la misma condición vital, por no decir fisiológica, del poeta» (2010: 368). En síntesis, descartados los cuatro sonetos de signo vitalista que formarían parte de Imagen de tu huella, Hernández incluyó en su nuevo libro I4 poemas inspirados en la pintora gallega. Salvo el soneto 22, «Vierto la red, esparzo la semilla», que remite al contenido de los cuadros Mensaje del mar y La red, composiciones de Maruja Mallo para la serie La religión del trabajo, los otros $\mathrm{I} 3$ representan plenamente la cosmovisión hernandiana que da carta de naturaleza al tema taurino y a su simbología. Se trata de los poemas I, 2, 3, 8, I4, I5, I6, I7, 20, 23, 26, 27 y 28: «Un carnívoro cuchillo», «¿No cesará este rayo que me habita?», «Guiando un tribunal de tiburones», «Por tu pie, la blancura más bailable», «Silencio de metal triste y sonoro», «Me llamo barro, aunque Miguel me llame», «Si la sangre también, como el cabello», «El toro sabe al fin de la corrida», «No me conformo, no: me desespero", «Como el toro he nacido para el luto», «Por una senda van los hortelanos», «Lluviosos ojos que lluviosamente» $\mathrm{y}$ «La muerte, toda llena de agujeros».

El último comentario corresponde a María Cegarra, por ser la receptora de las composiciones, a nuestro entender, del más auténtico aire petrarquista. Los quebrantos platonizantes de Miguel alcanzan en los sonetos inspirados en ella un tono más sereno, idealizado y evocador. A la luz de las cartas de poeta, de la conocida historia de la autora de La Unión, el recuerdo del hermano muerto y ese retiro en un pueblo «desolado y triste», podemos hallar suficientes elementos como para identificar en el conjunto los poemas inspirados en María. En dos de ellos, por ejemplo, aparece el recuerdo de su hermano Andrés Cegarra -«...de nostalgia tienes inclinado / medio cuerpo hacia mí, medio hacia el hoyo.» (Hernández 20I0:425) - mientras se escuchan las sirenas de las minas:

Angustia tanto el son de la sirena oído siempre en un anclado huerto, tanto la campanada por el muerto que en el otoño y en la sangre suena ${ }^{\mathrm{IO}}$.

Io Segunda estrofa del soneto «Fatiga tanto andar sobre la arena» (Hernández 20I0: 432). 
El silencio de María se hace visible en otro soneto. La muchacha no contesta a sus cartas (la joven se aísla y rechaza los brazos del poeta) y aflora el recuerdo de esa flor que ella puso en las manos de Miguel cuando se despidieron en los campos de La Unión:
Exasperado llego hasta la cumbre
de tu pecho de isla, y lo rodeo
de un ambicioso mar y pataleo
de exasperados pétalos de lumbre.
Pero tú te defiendes con murallas
de mis alteraciones codiciosas
de sumergirte en tierra y océanos.
Por piedra pura, indiferente, callas:
callar de piedra, que otras y otras rosas
me pones y me pones en las manos ${ }^{\mathrm{II}}$.

En contraste con la intemporalidad del resto de composiciones, los versos inspirados en María Cegarra aluden a un momento preciso, a un beso que se quedó en deseo, a un día y a un paseo, el único que en verdad compartieron en el verano de 1935:
Y recuerdo aquel beso sin apoyo que quedó entre mi boca y el camino de aquel cuello, aquel beso y aquel día ${ }^{12}$.
Y ayer, dentro del tuyo, me escribiste que de nostalgia tienes inclinado medio cuerpo hacia mí, medio hacia el hoyo ${ }^{13}$.

A partir de estos datos, podríamos atribuir a María Cegarra los sonetos I3, 2I, 24, 25 y 30 (Soneto final): «Mi corazón no puede con la carga», «iRecuerdas aquel cuello, haces memoria...?», «Fatiga tanto andar sobre la arena», «Al derramar tu voz su mansedumbre» $\mathrm{y}$ «Por desplumar arcángeles glaciales».

Siendo consecuentes con lo expuesto hasta aquí, defendemos la hipótesis de que el libro contiene Io composiciones inspiradas en Josefina Manresa, I4 en Maruja Mallo y 5 en María Cegarra, última en incorporarse al pere-

II Versos del soneto «Al derramar tu voz su mansedumbre» (Hernández 2oro: 433).

I2 Última estrofa del soneto «¿Recuerdas aquel cuello, hacer memoria...?» (Hernández 20IO: 43I).

I3 Última estrofa del soneto «Mi corazón no puede con la carga» (Hernández 20IO: 425). 
grinaje amoroso del poeta, esto es, cuando El rayo que no cesa se encontraba en una fase muy avanzada de escritura.

\section{Conclusión}

La conclusión a la que nos acercamos sitúa a la pintora Maruja Mallo en el eje principal del poemario amoroso de Hernández (Ferris 20I9: 83-84). Y para afianzar esa idea contamos con un dato revelador que nos permite valorar la importancia que la experiencia con la artista gallega llegó a tener para Miguel. Nos referimos a la distribución final de los poemas y el propio título de la obra. Se trata del último paso en ese proceso que había consistido en seleccionar los 29 poemas del libro (la inclusión de la «Elegía», escrita tras la muerte de Ramón Sijé, vino impuesta por las circunstancias). Y en esta tarea, nada trivial y mucho menos acumulativa, la labor del poeta es fundamental ya que de una estructura ordenada - concienzuda o instintivamente ordenada-depende el sentido pleno de la obra. Sobre este asunto, no es de extrañar que Miguel se sirviera del consejo de Vicente Aleixandre, a quien solía visitar semanalmente:

Me parece magnífico que pienses en sacar ya tu libro -le escribía el poeta andaluz un tiempo después, hallándose Hernández en el frente-: me gustaría estar contigo para ir viendo, con ese gozo que los poetas ponemos en estas cosas, la selección de tus poemas, la ordenación, esa manera de ir fraguándose un libro como cuerpo vivo, hasta tomar su forma... ${ }^{14}$.

Bien en soledad, bien con la valiosa supervisión y el consejo de Aleixandre, Miguel abrió el libro con el poema «Un carnívoro cuchillo», escrito en redondillas de rima alterna. Colocó, después, trece sonetos y, seguidamente, situó en el centro de la obra, a modo de eje, una larga composición (silva polimétrica) titulada «Me llamo barro». A continuación, completó el poemario con trece sonetos más, una «Elegía» escrita en tercetos encadenados y un «Soneto final».

El resultado - esa ordenación nada aleatoria- podemos apreciarlo en el siguiente esquema, de un equilibrio bastante elocuente, y del que se desprende, por su disposición, casi una historia narrada al hilo de los acontecimientos.

I4 Carta de Vicente Aleixandre fechada en Madrid el I2 de abril de I937, recogida en De nobel a novel. Epistolario inédito de Vicente Aleixandre a Miguel Hernández y Josefina Manresa (Riquelme 2015: 13I). 
JM: Josefina Manresa / MM: Maruja Mallo / MC: María Cegarra

I. Un carnívoro cuchillo (MM)

2. ¿No cesará este rayo...? (MM)

3. Guiando un tribunal (MM)

4. Me tiraste un limón (JM)

5. Tu corazón (JM)

6. Umbrío por la pena (JM)

7. Después de haber cavado (JM)

8. Por tu pie (MM)

9. Fuera menos penado (JM)

Io. Tengo estos huesos (JM)

II. Te me mueres de casta (JM)

I2. Una querencia tengo (JM)

I3. Mi corazón no puede (MC)

I4. Silencio de metal (MM)

I5. Me llamo barro (MM)
I6. Si la sangre también (MM)

I7. El toro sabe al final (MM)

I8. Ya de su creación (JM)

19. Yo sé que ver (JM)

20. No me conformo (MM)

2I. ¿Recuerdas aquel cuello? (MC)

22. Vierto la red (MM)

23. Como el toro (MM)

24. Fatiga tanto andar (MC)

25. Al derramar tu voz (MC)

26. Por una senda van (MM)

27. Lluviosos ojos (MM)

28. La muerte (MM)

30. Soneto final (MC)

Si tomamos como centro del libro el poema «Me llamo barro» y omitimos del citado esquema la Elegía (poema 29), de las diez composiciones vinculadas a Josefina Manresa y al pasado amoroso de Miguel, ocho aparecen en la primera parte y solo dos en la segunda. Cuatro de los cinco sonetos asociados a María Cegarra están situados en la segunda parte y, de ellos, uno cierra la obra. La presencia de Maruja Mallo en los catorce poemas que a ella atribuimos está repartida con relativa proporción en ambas mitades: cinco composiciones en la primera parte, ocho en la segunda y una en el eje de la obra.

Tanto el título del libro como la metáfora de ese rayo incesante nos conducen, entre otros, al soneto «Una querencia tengo por tu acento»

I5 En el primer terceto de este soneto, en su versión primitiva, se podía leer: «iAy querencia, dolencia y apetencia!: / me falta el aire tuyo, mi sustento, / y no sé respirar, y me desmayo». Sin embargo, en el poema definitivo, con los cambios realizados, lo que nos sugería el autor era que le urgía recurrir al antídoto de los besos que siempre le negó Josefina para no caer rendido en los brazos de la pintora que ahora ocupaba su pensamiento: «iAy querencia, dolencia y apetencia!: / tus sustanciales besos, mi sustento, / me faltan y muero sobre mayo» (Hernández 
se advertía ya la presencia de Maruja en la vida del poeta cuando este aún mantenía su noviazgo con Josefina. En él, Hernández rescataba unos versos escritos en 1934 para reclamar ahora la ayuda de la joven pueblerina ante la tentación de esa mujer que representaba lo dinámico, la tormenta que empezaba a ocupar su pensamiento, el rayo que venía a desbaratar su tranquilo amor juvenil. Maruja iba a ser, desde aquel momento, el «eterno rayo» que cobraría categoría de símbolo absoluto en esa otra forma verbal -«rayo que no cesa»- destinada a hacer estragos en su vida. El poema «Mis ojos, sin tus ojos, no son ojos» de Imagen de tu huella, poblado de vitalismo y de gratitud del enamorado que se ve realizado como hombre y como ser gracias a la amada, trasforma en El rayo que no cesa la dulce huella en pisada perversa que aplasta y humilla al confiado amante. Mientras tanto, el poeta, que sabe lo que duele ese desdén, eleva su sentimiento al máximo en uno de los poemas más profundos y amargos de su producción lírica: «Me llamo barro aunque Miguel me llame». El testimonio amoroso que nos deja en esta pieza merece la mirada atenta del lector. El autor lo ha colocado con precisión en el centro de su libro para concederle esa preponderancia estructural que enfatice su importancia y su valor. Ni siquiera es un soneto, sino una larga composición (silva) de trece estrofas irregulares y sesenta y un versos que el poeta ha dejado a propósito en ese lugar -presidiendo el conjunto desde una privilegiada posición y flanqueada por dos series de sonetos- como el testamento de un amor que ha agitado con fuerza su existencia. El grado de erotismo, de delirio sensual; el canto a la materia -carne o barro-, alcanzan aquí toda la grandeza imaginativa y terrenal de un Hernández verdaderamente herido por la vida. No en vano, el juego que el poema propone ha dado pie a interpretaciones muy audaces que no vamos a defender, aunque sí tomaremos el discurso hernandiano como una manifestación erótica que recurre a la fórmula metafórica del pie sobre el cuerpo -labios, boca, lengua- para hacer más expresiva la sensación de ultraje:

Apenas si me pisas, si me pones

la imagen de tu huella sobre encima,

se despedaza y rompe la armadura

de arrope bipartido que me ciñe la boca

en carne viva y pura,

pidiéndote a pedazos que la oprima

siempre tu pie de liebre libre y loca (Hernández 20I0: 427).

2010: 425). El guiño nos parece claro y revelador: «mayo/Mallo». El poeta sabía, pese a su distanciamiento del catolicismo, que Josefina era la voz de lo sereno, lo puro, lo ajustado a esa moral religiosa que aún latía en un lugar de su conciencia. Maruja Mallo encarnaba, por el contrario, el pecado, la tormenta que sacudía su vida, el rayo que había venido a destrozar su tranquilo amor juvenil. 
Con El rayo que no cesa, el poeta daba por acabada una etapa honda y compleja de su vida, de la que había salido entero pero lastimado. En el camino había ido dejando pedazos de sí mismo y de una crisis espiritual que aún no se podía dar por cerrada. Faltaban unas semanas para que el año I935 concluyera y quedaban acontecimientos por vivir que iban a dejar también su huella esperanzadora, su huella amarga, en el corazón del poeta.

\section{Bibliografía}

Alemany Bay, Carmen, Miguel Hernández, el desafío de la escritura. Proceso de creación de la poesía hernandiana, Madrid, Visor, 2013.

Balcells, José María, Miguel Hernández, corazón desmesurado, Barcelona, Dirosa, 1975.

—. «De Josefina a María, y de María a Maruja», en Homenaje a María Cegarra, ed. Santiago Delgado, Murcia, Editora Regional de Murcia, I995, pp. I63-I7I.

Domínguez García, T., «Yo te libé la flor de la mejilla”: El antipetrarquismo en El rayo que no cesa», en Presente y futuro de Miguel Hernández, Actas de II Congreso Internacional, Orihuela-Madrid, 26-30 octubre 2003, Orihuela, Fundación Cultural Miguel Hernández, 2004, pp. 283-300.

Ferris, José Luis, Miguel Hernández. Pasiones, cárcel y muerte de un poeta, Madrid, Temas de hoy, 2002.

-. «La amada plural en El rayo que no cesa», en Presente y futuro de Miguel Hernández, Actas del II Congreso Internacional. Orihuela-Madrid, 26-30 octubre 2003, Murcia, Fundación Cultural Miguel Hernández, 2004a, pp. 49-77.

- Maruja Mallo. La gran transgresora del 27, Madrid, Temas de Hoy, 2004b.

- Carmen Conde. Vida, pasión y verso de una escritora olvidada, Madrid, Temas de Hoy, 2007.

—. «Eros y Psique en El rayo que no cesa», en Canelobre, Miguel Hernández, cien años, 56, Invierno, 2009-20Io, pp. 48-67.

- Miguel Hernández. Pasiones, cárcel y muerte de un poeta, Madrid, Temas de hoy, 2 oro.

- Miguel Hernández. Pasiones, cárcel y muerte de un poeta, Madrid, Fundación José Manuel Lara, 2016.

-. Maruja Mallo, Madrid, Editorial El País, 2019.

Guerrero Zamora, Juan, Noticia sobre Miguel Hernández, Madrid, Cuadernos de Política y Literatura, I95I.

Hernández, Miguel, El rayo que no cesa, pról. José María de Cossío, Espasa-Calpe, Buenos Aires, 1949.

-. El rayo que no cesa, intr. José María Balcells, Murcia, SIAL Ediciones, Madrid, 2002.

—. Obra completa, Madrid, Espasa Calpe, 20 Io. 
Luis, Leopoldo de, Aproximaciones a la obra de Miguel Hernández, Madrid, Ediciones Libertarias, 1998.

Mainer, José-Carlos, «Apuntes sobre el tema rural en la España republicana», en Miguel Hernández, cincuenta años después. Actas del I Congreso Internacional. Alicante, Elche, Orihuela, marzo de 1992, Alicante, Comisión del Homenaje a Miguel Hernández, I993, pp. 29-35.

Mallo, Maruja, Carpeta Homenaje a la Revista de Occidente, Madrid, Fundación Ortega y Gasset, 1979.

Martín, Eutimio, El oficio de poeta. Miguel Hernández, Madrid, Aguilar, 20 o.

Martos Pérez, M. D., «El petrarquismo en El rayo que no cesa», en Presente y futuro de Miguel Hernández, Actas del II Congreso Internacional, OrihuelaMadrid, 26-30 octubre 2003, Orihuela, Fundación Cultural Miguel Hernández, 2004, pp. 267-282.

Morelli, Gabriele, «Mi primer encuentro con Josefina Manresa. Entre realidad y memoria», Canelobre, 56, invierno, 2009-20Io, pp. 230-243.

-. «En torno a Josefina Manresa», en Un cósmico temblor de escalofrío. Estudios sobre Miguel Hernández, eds. Francisco J. Díez de Revenga y Mariano de Paco, Murcia, Fundación CajaMurcia, 20Io, pp. 249-263.

-. Epistolario inédito sobre Miguel Hernández (I96I-I97I) entre Dario Puccini y Josefina Manresa, Sevilla, Ediciones Espuela de Plata, 201.

Navarro Colorado, Borja, «El empaque clásico de El rayo que no cesa de Miguel Hernández. Un análisis computacional y distante», en Miguel Hernández. Poeta en el mundo. Actas del IV Congreso Internacional. Orihuela, Elche, Alicante. Noviembre 20I7, Alicante, Instituto Alicantino de Cultura Juan Gil-Albert, 2020, pp. 543-558.

Riquelme, Jesucristo, De nobel a novel. Epistolario inédito de Vicente Aleixandre a Miguel Hernández y Josefina Manresa, ed. J. Riquelme, Madrid, Espasa Calpe, 2015.

—. Epistolario general de Miguel Hernández, Madrid, Edaf, 2019.

Sánchez Vidal, A., «Introducción» a Miguel Hernández, Obra Completa, vol. I, Poesía, Madrid, Espasa Calpe, I992, pp. 29-48. 